\title{
IMPACT OF ONLINE TEACHING TECHNIQUES ON STUDENT ENGAGEMENT IN ENGINEERING DYNAMICS
}

\author{
Ahmad Ghasemloonia and Meera Singh \\ Department of Mechanical and Manufacturing Engineering, University of Calgary \\ ahmad.ghasemloonia@ucalgary.ca, meera.singh@ucalgary.ca
}

\begin{abstract}
Engineering Dynamics has historically been one of the most challenging courses in the engineering curriculum. At this institution, Dynamics is taken by approximately 500 students annually and the failure rate has been between $15-20 \%$ for the past 10 years. This rate has serious implications on program length and student retention. In the last few years, comprehensive studies have been conducted by the authors aimed at improving these statistics. Plans to focus further on improving student engagement in Dynamics were made critical in Fall 2020 due to the COVID-19 pandemic and the consequential requirement that it had to be offered completely online.

The primary objective when setting up this online offering of Dynamics was to maximize student engagement while leveraging the new possibilities of online education. This paper reflects on the impacts of the details of the course structure on student engagement. In addition to student outcomes, student survey results associated with the impacts of online learning are analyzed. Some challenges are identified that require further focus and evaluation. It is concluded that student outcomes in Engineering Dynamics may benefit post-pandemic by implementing some of the online learning techniques adopted in Fall 2020 in a blended course delivery.
\end{abstract}

Keywords: Student Engagement, Online Learning, Engineering Dynamics, Faculty-Student Interaction, Learning Styles, Mastery Learning.

\section{INTRODUCTION}

Efforts to improve outcomes in Engineering Dynamics at the University of Calgary have focussed on student learning styles and assessments. In [1], Singh et. al. gave the index of learning style (ILS) survey [2] that is based on the Felder-Silverman learning style model [3] to the 2015 dynamics class at the University of Calgary. Data analysis revealed that students in the class had learning styles that were more active than reflective, more sensing than intuitive, more visual than verbal, and more sequential than global. The study revealed the need to overcome systemic barriers to student learning, a more balanced approach to teaching, and the provision of more frequent active learning opportunities. As a result of the study [1], lecture demonstrations were designed, and lectures were delivered in a more engaging and interactive manner. In [4] Ghasemloonia and Singh focussed on Bloom's philosophy of mastery learning [5] and revisited assessment methods accordingly. They implemented regular assessments to provide feedback opportunities and a second chance testing program for quizzes and the midterm exam as vehicles to promote mastery learning goals. Apart from slightly improved outcomes, survey results suggested that the assessment program acted to reduce student stress, was motivating, and positively impacted the students' understanding of dynamics.

Although it has been possible for campus-based students to study fully online for some time, the use of educational technology in engineering courses has lagged developments therein. In Engineering Dynamics, only asynchronous educational tools such as the use of learning management platforms had been implemented. Instructors had contemplated blended learning models but chose to focus on optimizing fully in-person courses before conquering the complexities of their implementation. In other words, like many other academics, critically evaluating the plethora of evidence-based research associated with fully online or blended delivery and learning the associated tools, was not deemed of relative critical importance. However, the global health crisis associated with the COVID-19 pandemic necessitated a swift reimagination of university-wide course delivery. In the middle of the Winter, 2020 term, academics were required to immediately shift courses developed for inperson delivery to fully digital delivery.

Fortunately, Engineering Dynamics was next delivered in the Fall of 2020 and instructors had the Spring and Summer reflect on their courses taught in Winter, 2020 after the shift to online, and prior research [1], [4] that had been conducted within Dynamics to improve student outcomes. In developing the course for online delivery, the 
direction of inquiry naturally shifted towards how to responsibly engage students in the online environment.

There has been an abundance of research conducted on student engagement that focuses on bringing clarity to its definition and developing associated theory and best practices. Literature reviews can be found in articles such as [6]. The National Survey of Student Engagement (NSSE) is the benchmark tool used to measure student engagement in North American academic institutions. It measures engagement among four themes including academic challenge, learning with peers, experiences with faculty, and campus environment [7]. It is based on Chickering and Gamson's [8] widely cited article entitled "Seven Principles for Good Practice in Undergraduate Education". These principles include student-faculty interaction, reciprocity and cooperation among students, active learning, encourages prompt feedback, time on task (in quality instruction), communication of high expectations, and respects diverse talents and learning styles. Although developed for in-person classes, the use of foundational concepts has been studied in their application to online classes [9]-[11]. These studies emphasize the importance of applying the seven principles for good practice in online learning [9], suggest guidelines for the applications of the seven principles to online learning environments [10], and discuss the use of technology to facilitate the seven principles [11]. Many articles such as [12] have suggested that student-student and instructor-student communication should be of critical focus in the online environment.

In the developing Engineering Dynamics for online delivery, the primary goal was, at a minimum for the average outcomes of the 496 students enrolled to not deviate significantly from past offerings. To maximize student engagement, the authors built on research conducted in [1], and [4], and focussed Chickering and Gamson's [8] principles of good practice, with emphasis on building multiple levels of communications in all elements of course design. In addition to hosting synchronous online lectures, tutorials, daily office hours, and exam review sessions, instructors posted all lecture and tutorial videos, weekly assignments and solutions, sample solved problems, review assignments, and old exams. Students were offered the opportunity to master content by writing a make-up midterm with constraints. Although similar in length and difficulty level to previous course offerings, the format of the online assessments was completely redesigned with student stress, academic integrity, and the constraints associated with the online assessment tools in mind.

In this study, these delivery methods and tools used are first detailed in the context of maximizing student engagement. A student survey designed to measure the impact that delivery tools and delivery methods had on student engagement is then outlined. Results of the survey are presented and discussed, and student outcomes are assessed and compared to those obtained in prior years where applicable. The discussion focuses on what worked and what did not work as related to student engagement. Conclusions are drawn regarding the best type of Dynamics course delivery method that should be implemented post-pandemic.

\section{FORMAT OF ONLINE COURSE}

\subsection{Lectures}

All students $(n=496)$ required to take the second year Dynamics class (mechanical, civil, chemical) were taught in one lecture section. The three weekly 50 -minute lectures were delivered online via Zoom. They were conducted in a live synchronous manner to promote student-instructor and student-student contact and foster a community of engaged learning. Fillable lecture notes were uploaded at the start of the semester on the course Desire to Learn (D2L) site. The instructor used a tablet in screen share mode to fill in the lecture notes and to regularly solve relevant example problems. The instructor promoted active participation in the online lectures by focusing on student-centered interactive discussions about the material and other small tasks that they were regularly asked to complete. The synchronous sessions were recorded and uploaded on the course D2L site. Although this may have contributed to the relatively poor attendance in the synchronous lectures $(\sim 40 \%$ vs $90 \%$ in previous oncampus offerings), it was felt that posting the synchronous lectures was critical in respecting different learning styles. Furthermore, recorded lectures could be watched and rewatched by students to reinforce the material and were critical in accommodating students who are living in different time zones. It should be noted that posting recorded lectures could result in students watching lectures at an increased speed (e.g., 1.5X speed) and this may have deleterious effects on students' learning in this challenging course.

\subsection{Tutorials}

There was a 75-minute synchronous tutorial each week. The tutorials were divided into two parts. The first 35 minutes was used to solve a comprehensive problem that covered the assignment for the week and prepared students for the quiz in the second part of the tutorial. The tutorial problem was posted on the course website before the tutorial session to satisfy both the active and reflective learners. To promote active learning in the limited time available in the synchronous tutorials, students were encouraged to post questions on the Zoom chat board. An experienced teaching assistant monitored the chat session, answered one-off student questions therein, and immediately brought all repeated questions to the attention instructor to answer to the whole class. When time permitted, open class discussions were encouraged. Like 
the synchronous lectures, the tutorial sessions were recorded and posted on the course website to facilitate students in different time zones. Since the quiz was held right after the tutorial and based on the same material as the tutorial problem, the attendance in the tutorial sessions was above $90 \%$.

\subsection{Online Posted Material}

The course-related materials were posted on the course D2L site. As mentioned, a complete set of fillable lecture notes was posted as a single PDF at the beginning of the term. In doing so, students could download and print the notes or use them on their tablets. A table of the course coverage schedule which showed the corresponding sections in the course recommended textbook in the lecture notes was also posted.

The instructors posted a variety of additional materials designed to accommodate different learning styles, provide opportunities for interactions, and opportunities to increase the time on task in Dynamics. Each week, the instructors posted an assignment of five questions based on the lecture material covered. The assignment consisted of approximately 4-5 questions and was not graded. The numerical answers were provided with the assignments, however full solutions of assignments were posted after the tutorial session the following week. The students were encouraged to first work individually on the assignments before collaborating with their peer groups. The intention was to promote a period of reflection (as recommended in [4] and student-student interaction. To complement the assignments, the instructors also posted sample solved problems with weekly assignments. This worked to provide the more reflective learners additional materials to reference when completing the assignment. Additional practice problems for each chapter were posted after the instructors covered each chapter. Finally, sample quizzes, midterms, and sample final exams were posted on the course website.

\subsection{Other Opportunities for Student-Faculty Interaction}

Apart from the live lectures and tutorials, daily 75-minute office hours were held over Zoom. During office hours, students would enter into the Zoom virtual office and the instructor would answer questions on the tablet in screen share mode. Normally, students would stay in the office hours for long periods and listen to other student's questions and interact when appropriate. Students were encouraged to request private sessions in break-out rooms if desired. Using this format, it was found that the students not only benefitted from the interaction with the instructor, they also interacted with each other. Although not widely publicized, on-demand office hours were often provided to students who could not attend those that were scheduled. On days just before assessments, office hours were busy and questions were content related. On other days, students often came to the office hours to discuss other issues that they were having with online learning.

In an attempt to provide immediate feedback to the students and to encourage instructor-student interaction, the instructors had a 24-hour response policy on emails and encouraged students to contact them with their technical questions and any other course related issues. Although time consuming in a class of almost 500 students, it was felt that a quick response to emails was critical to keep the line of communication between the students and instructors continuously open. Finally, the instructors held a 3-hour final exam review session over Zoom. This session was designed to foster the culture of successful exam preparation and reduce student anxiety before the final exam.

\subsection{Assessments}

The course assessment components included 7 quizzes (the first quiz was a practice quiz), a midterm (with the opportunity of writing a make-up midterm), and a final exam. The weight of quizzes was $25 \%$, the midterm $25 \%$, and the final exam's weight was $50 \%$. All students were required to write the original midterm. If the students chose to write the make-up midterm, it would account for $70 \%$, and the original midterm accounted for $30 \%$ of the midterm grade. If a student chose not to write the make-up midterm, then the original midterm grade accounted for $100 \%$ of their midterm grade.

To promote immediate feedback and minimize opportunities for academic misconduct, the instructors chose to pilot the use of the quiz functionality on the D2L platform. The typical long answer exam questions given in in-person exams were decomposed into many smaller questions with randomized inputs. All the assessment components were numerical answer only and no work was submitted by students. The questions were made numerically independent of each other so that errors could not propagate forward. University regulations did not permit online proctoring and required that $50 \%$ additional time over the design time was given to the students to accommodate any issues that the students may have experienced during an online assessment. All of the assessments were synchronous (started and ended at the same time) for all students. To accommodate students in different time zones and students who may have had difficulties in writing the exam at the scheduled time, any student could request to write an examination at a time other than that scheduled, provided that the requested start time fell within the 24 hours preceding the examination. Full solutions of all quizzes and examinations were posted on the course website and students could access the graded assessments within 24 hours of writing them. 


\section{STUDENT SURVEY RESULTS AND DISCUSSION}

To receive feedback from students, the instructors conducted two surveys in the final exam preparation session. These surveys were conducted completely anonymously via the poll option in Zoom. Sixty percent of the students $(n=297)$ participated in the surveys. The first survey related to the structure of the course and student engagement. The second survey was a continuation of the research conducted by the authors in [4] on mastery learning and focussed on the midterm reassessment. Both surveys asked the students to use a 5-point Likert ((1) Strongly Disagree; (2) Disagree; (3) Neither agree nor disagree; (4) Agree; (5) Strongly Agree) in their responses to all (but one) of the questions.

There were 10 questions in the first survey. The questions are copied below, and the results are shown in Fig. 1.

Q1: You prefer online lectures and tutorials over inperson lectures and tutorials.

Q2: You preferred the synchronous lecture (as was in this course) over pre-recorded lectures in other courses that you may have taken.

Q3: You accessed the uploaded recordings of the lectures when you had difficulties with a concept in the course.

Q4: You had sufficient access to the professors to ask questions.

Q5: Because the quizzes and exams were held at a fixed time and not in a 24-hour (with set access duration) format, it increased your overall stress level in writing them.

Q6: The quizzes and exams were held at a fixed time, and questions contained randomized numbers. For these reasons, you feel that the course maintained a high standard of academic integrity.

Q7: Because the quizzes and exams were held at a fixed time and not in a 24-hour (with set access duration) format, it increased your overall stress level in this course.

Q8: The quizzes helped you to keep up with the course material.

Q9: There were too many quizzes in this course and they unnecessarily increased the overall stress level in the course.

Q10: You experienced technical difficulties with your computer/internet when you were completing the exam.

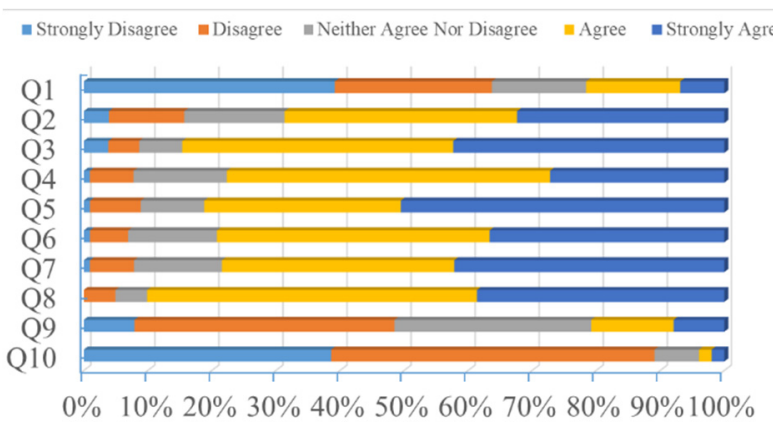

Fig. 1. Survey results about online teaching.

At a first glance, the results from Question 1 indicate that students preferred in person over online lectures and tutorials. However, other large contributing factors to this response such as social isolation due to the pandemic may have impacted the results. The results from Question 2 indicate that synchronous lectures with the uploaded recordings are preferred by students over asynchronous posted lectures. This is not surprising since the synchronous lectures increase contact between students and professors and provided a platform for them to engage in the discussions in the lectures. In Question 3, more than $80 \%$ of students agreed or strongly agreed that they accessed the uploaded recordings of the lectures and tutorials. The recordings enabled instructors to acknowledge reflective learners, provided the opportunity for more time on task, and gave those students who do not learn completely in the lectures the opportunity to re-watch the lectures at will. Approximately $80 \%$ of the participants confirmed that they had enough access to the instructors to ask questions (Question 4). This confirmed that ample opportunities were provided for student-professor interactions in lectures, tutorials, and office hours. As stated in the previous section, daily office hours, responding to emails in less than 24 hours are great tools to maintain contact between students and professors. Although students felt like the timed exams in the course increased their stress level (Question 5), they also believed that because of the timed exam with randomized numbers, the course maintained a high level of academic integrity (Question 6). Although the course instructors agree that timed exams might cause anxiety, in online exams without proctoring, this was the only tool that instructors had to maintain academic integrity without changing to more project-based assessments. Additionally, the majority of participants stated that having seven quizzes in the course helped them keep up to date with the course material (Question 8). Having regular quizzes enabled students to receive continuous feedback during the semester and not only after the midterm and the final exam. Additionally, quizzes informed students of the instructor's expectations regarding the required level of understanding throughout the term. This is also evidenced in the response to Question 9 where, although the synchronous nature of the exams increased the student's overall stress level), $80 \%$ of the 
students indicated that the number of quizzes did not contribute to increased student stress in the course. The response to Question 10 indicates that almost $90 \%$ of the students did not experience technical difficulties while writing the assessments and just 5\% of students reported technical difficulties. This result may suggest that the 50\% contingency time may have not been completely necessary for the entire class.

The second survey was designed to assess the impact of the make-up midterm on student content mastery. The questions are copied below and the survey results are shown in Fig. 2.

Q1: You studied less for the original midterm knowing that you had an opportunity to rewrite it.

Q2: The make-up midterm formed a good motivation to learn material that you did not originally have time for when you wrote them the first time.

Q3: Overall, you perceived that the make-up midterm to be much easier, slightly easier, about the same, slightly harder, much harder than the midterm.

Q4: You wish that you could have the opportunity to rewrite quizzes in this course.

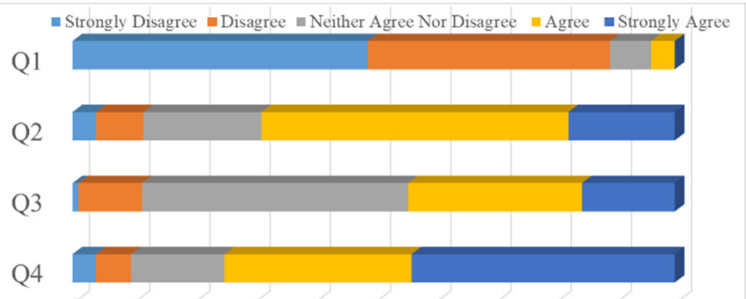

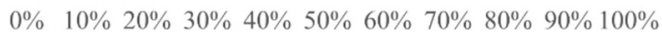

Fig. 2. Survey results about the make-up midterm.

The $30 \%$ and $70 \%$ contribution of the midterm and make-up midterm grades respectively to the final midterm grade was chosen to prevent students from not studying for one with the knowledge that they will have another opportunity to improve their grade. This increased the time on task for these students. The responses to Question 1 confirmed that they did study for the original midterm despite their outcome. The responses to Question 2 suggest that the make-up midterm formed a tool that encouraged students to learn the concepts that they had difficulties with before moving on to the next section of the course. This is critical in dynamics since the midterm covers the kinematics and dynamics of particles, topics that students must be comfortable with before moving on to rigid bodies after the midterm. Although the experienced instructors designed the two midterms to be of the same length, format, and difficulty level, $45 \%$ of the participants perceived the make-up midterm to be slightly harder or much harder than the original midterm. The students appreciated the opportunity to increase their understanding and grade as almost $80 \%$ of them wished to have the same opportunity to rewrite the quizzes (Question 4).

CEEA-ACEG21; Paper 179

University of Prince Edward Island; June $21-23,2021-5$ of 7 -

\section{DisCUSSION OF STUDENT OUTCOMES}

In this section, average results of the online quizzes, midterm, make-up midterm, and final exam are presented and compared to those obtained in the Fall, 2019 in-person course offering, taught by the same instructors and attended by approximately the same number of students. In Table 1, the averages on assessments are compared.

Table 1: Comparison of In-Person (2019) and Online (2020) Student Outcomes on Assessments

\begin{tabular}{|c|c|c|c|}
\hline $\begin{array}{c}\text { Assessment } \\
\text { Type }\end{array}$ & $\begin{array}{c}\text { Average 2019 } \\
\text { In Person (\%) }\end{array}$ & $\begin{array}{c}\text { Average } \\
2020 \\
\text { Online (\%) }\end{array}$ & Change \\
\hline Quizzes & 73 & 72 & $-1 \%$ \\
\hline Midterm & 68 & 56 & $-12 \%$ \\
\hline $\begin{array}{c}\text { Make-up } \\
\text { Midterm }\end{array}$ & 78 & 64 & $-14 \%$ \\
\hline Final Exam & 68 & 71 & $+3 \%$ \\
\hline
\end{tabular}

It is interesting to note that students did better on the inperson quizzes and midterms than they did on the online counterparts. The use of the D2L quiz function and the associated reformatting of the exams may have contributed to this result. However, this does suggest that the steps taken to minimize academic misconduct (synchronized exams and randomized numbers) were somewhat successful.

The midterm results for both years are broken down further in Table 2. The table focuses only on the students who chose to write the make-up midterm. It should be noted that in both F2019 and F2020, 56\% of the students enrolled opted to write the make-up midterm. The table suggests that in the in-person course delivery, the students who opted to write the make-up midterm, improved their marks by $23 \%$ by doing so. This improvement was less in the online delivery $(+15 \%)$. Since the final exam marks were slightly better in the online delivery, it is felt that the students may have been struggling to adjust to the aforementioned format of the online exams at the midterm and may have overcome their associated difficulties by the final exam. This result provides a reason for why the students associated more stress with the online assessments.

Table 2: Midterm and Make-up Midterm Averages

\begin{tabular}{|c|c|c|}
\hline & $\begin{array}{c}\text { Average 2019- } \\
\text { In Person (\%) }\end{array}$ & $\begin{array}{c}\text { Average 2020 } \\
\text { Online (\%) }\end{array}$ \\
\hline Midterm & 54 & 49 \\
\hline $\begin{array}{c}\text { Make-Up } \\
\text { Midterm }\end{array}$ & 78 & 64 \\
\hline Change & $+23 \%$ & $+15 \%$ \\
\hline
\end{tabular}




\section{Conclusions}

This paper details the online Dynamics class that was designed to foster student engagement. Student-faculty contact was fostered by implementing synchronous lectures and tutorials, holding daily office hours, a final exam review session, and being dedicated to a 24-hour response time to student emails. The survey results suggested that students felt that they had ample access to the professors. On the other hand, the only opportunity that students were provided by the instructors for studentstudent interaction was the not for credit assignments where they were encouraged to work with peers. This may have contributed to the student's response on the survey that they preferred in-person lectures and tutorials over their online counterparts. For future online or blended deliveries, digital tools such as discussion boards or social media sites are recommended to facilitate these interactions. Although academic misconduct was not an obvious concern in this class, it is felt that providing and participating in such venues may help deter a subculture of students who use social media to access other students during assessments.

A balanced approach to teaching was sought in the online course to address the diversity of learning styles that were identified in [4]. It was felt that there was little necessity to focus on the difference in the in-person versus online delivery methods to address sensing versus intuitive, visual versus verbal, and global versus sequential learning styles. Posting the synchronous lectures and tutorials online engaged the reflective learners. Care had to be taken to engage the active learners online where the opportunities for active engagement are less obvious than in in-person delivery. This was accomplished by conducting the lectures and tutorials in an interactive manner, by providing daily office hours, and by being dedicated to responding to student emails. Active learners would benefit from more peer-to-peer interactions as mentioned above than what was provided to them.

The online quizzes and midterms afforded feedback to the students on their understanding of the material approximately every 10 days. The students reacted positively to the frequent nature of the assessments. However, the students felt that the synchronous and timed nature of the assessments increased their overall stress level in the course. This was reflected most prominently on the midterm and make-up midterm exams where the online averages were less than the in-person averages the previous year.

The use of the D2L quiz platform enabled automated and prompt feedback after an assessment. Although the reduction in marking time allowed instructors and teaching assistants to focus more on interactions with the students, the associated numerical answer only requirement was not well received by the students. Furthermore, the instructors felt that some key concepts in dynamics such as drawing free body and kinetic diagrams could not be tested as well in the online quiz platform as they could be in long written solutions. For such aspects that are generally quick to mark, it is recommended that online assessments should allow for students to upload their written solutions.

Students were provided ample resources to increase their time on task. Apart from the posted written resources, the students responded well to the availability of the posted synchronous lectures. Having the ability to re-watch lectures is not available for on-campus lectures where students can potentially lose concentration and miss key concepts.

With the availability of educational technology, and the experience with it the Fall 2020 online delivery of dynamics, it is felt that a blended learning model can be implemented post-pandemic. Specifically, the authors encourage delivering and posting synchronous online lectures. In-person tutorials can be reimagined to focus on experiential learning opportunities and promote studentstudent interaction. Additionally, the use of technology for office hours is recommended to promote convenient faculty-student interaction. Although there was a reduction in marking time associated with online exams, the conventional long answer exam format is preferred by students. Finally, as in [4], it was found that the second chance exams promoted content mastery and should be provided for all assessments in dynamics.

\section{References}

[1] Meera Singh, Les Sudak, and Philip Egberts, "Mapping conventional teaching methods and learning styles in engineering dynamics, in" Proc. ASEE 123rd Annual Conference \& Exposition (New Orleans, LA; 2629June 2016), 17 pp., 2016.

[2] Richard M. Felder, and Barbara Soloman, "Index of learning styles questionnaire, 2001. https://www.engr.ncsu.edu/learningstyles/ilsweb.html. (Accessed February 4, 2020).

[3] Richard M. Felder and Linda K. Silverman, "Learning and teaching styles in engineering education," Engineering Education, vol. 78, no. 7, pp. 674-681, 1988.

[4] Ahmad Ghasemloonia and Meera Singh, "Using assessments to improve student outcomes in engineering dynamics". In Proc. ASEE ASEE Virtual Annual Conference (Virtual Online; 22-26June 2020), 17 pp., 2020.

[5] Benjamin Bloom, "Learning for mastery. Instruction and curriculum. Regional education laboratory for the Carolinas and Virginia, topical papers and reprints, Number 1," Evaluation Comment, vol. 1, no. 2, pp. 112,1968 .

[6] Vicki Trowler, Student Engagement Literature Review," Higher Education Academy, pp. 74, 2010. 
[7] George D. Kuh, "Assessing what really matters to student learning, Inside the national survey of student engagement," Change, the Magazine of Higher Learning, vol. 33, no. 3, pp. 10-17, 2001.

[8] Arthur W. Chickering and Zelda F. Gamson, "Seven principles for good practice in undergraduate education," The Wingspread Journal, vol. 9, pp. 1-10, 1987.

[9] Rena M. Palloff, Keith Pratt, and Denise Stockley, "Building learning communities in cyberspace: effective strategies for the online classroom," The Canadian Journal of Higher Education, vol. 31, no. 3, pp. 175-178, 2001.

[10] Arthur W. Chickering, and Stephen C. Ehrmann, "Implementing the seven principles of good practice in undergraduate education: Technology as lever," Accounting Education News, vol. 49, pp. 9-10, 1996.

[11] Renee E. Weiss, Dave S. Knowlton, and Bruce W. Speck, Principles of Effective Teaching in the Online Classroom. San Francisco, CA: Jossey-Bass, 2000, 110 pp. \{ISBN-10: 0787956155\}

[12] Marcia D. Dixon, "Creating effective student engagement in online courses: What do students find engaging?," Journal of the Scholarship of Teaching and Learning, vol. 10, no. 2, pp. 1-13, 2010. 